\title{
TRABAJOS DE INVESTIGACIÓN
}

METABOLISMO ÓSEO

\section{Presentación Oral}

\section{Fuerza muscular y composición corporal en la valoración del riesgo cardiovascular y fracturas en hombres y mujeres de población urbana y rural. Evidencia del mecanostato óseo}

\section{REX}

Introducción: Se estudiaron 600 hombres y mujeres pre y posmenopáusicas, divididos en 300 residentes urbanos (U) y 300 rurales (R). A todos se les evaluó dinamométricamente la fuerza muscular del puño no dominante (FP, valores medios de tres intentos, o valores máximos), y las masas óseas (CMO), magra (MM) y grasa (MG) del cuerpo entero y del miembro superior (MS) por DXA, y se analizaron comparaciones y correlaciones entre las distintas variables determinadas.

Resultados: 1. El CMO del MS fue mayor (ANOVA, p<0,001) en los hombres y mujeres preMP (no en las posMP) R que en los U. 2. La MM del MS fue mayor (ANOVA, $p<0,001$ ) en los individuos $\mathrm{R}$ que en los U. 3. La correlación entre la FP media o máxima (y) y la MM del MS (x) fue positiva, logarítmica y muy ajustada para todos los individuos juntos ( $\mathrm{r}$ globales $=0,771 \mathrm{y}$ $0,763, p<0,001)$. Los valores de los hombres plotearon despla- zados arriba y a la derecha y los de las mujeres pre y posMP, juntas, abajo y a la izquierda de la gráfica, sin distinción entre R y U. 4. Las correlaciones entre CMO y FP, significativas y logarítmicas, mostraron ordenadas significativamente más altas (ANCOVA) para hombres que para mujeres, y para los hombres y mujeres preMP R que U.

Conclusiones: Las correlaciones entre FP y MM indican que la MM es un indicador fidedigno de la fuerza de la musculatura, independiente del sexo, del estado reproductivo y del ambiente ecológico en el que se desempeña el individuo estudiado. Las diferencias entre U y R en la correlación entre CMO del MS y FP sugieren que la masa ósea no es solo función de la masa de la musculatura que la afecta, sino también de su fuerza, y del uso que se hace de ella, según predice la teoría del mecanostato óseo.

\section{Póster}

\section{Hiperparatiroidismo asociado a osteoporosis en paciente con cirugía bariátrica. Reporte de caso}

\section{Cuspoca A F, Tovar E A.}

Universidad Pedagógica y Tecnológica de Colombia, Corporación MI IPS Boyacá, Tunja, Colombia.

Objetivo: Realizar una revisión del caso clínico de una paciente con hiperparatiroidismo secundario a osteoporosis como consecuencia de una cirugía bariátrica.

Metodología: Se realizó un estudio descriptivo tipo reporte de caso seleccionando una paciente con diagnóstico de os- teoporosis secundaria a cirugía bariátrica e hiperparatiroidismo que asistió a IPS de primer nivel. Obteniendo información a partir de la historia clínica según la aprobación del comité de bioética de la institución y firma de consentimiento informado.

Resultados: Paciente femenina de 64 años, procedente de Tunja, refiere dificultad para actividad física por dolor poliarticular, astenia y adinamia. Antecedentes patológicos: HTA, hipotiroidismo no controlada, antecedentes quirúrgicos: bypass gástrico por laparoscopia (Y de Roux ) 2010, pa- 
raclínicos del 24-01-2017: niveles de vitamina D 25- hidroxi: 20,8 ng/ml, PTH: $91 \mathrm{mg} / \mathrm{dl}$, calcio iónico 4,70 mg/dL, fósforo inorgánico: 4,1 mg/dl, densitometría ósea 27/01/2017 Ds: columna lumbar: T Score: -2,7, Z Score: $-1,3$ fémur: T Score: -2,8, Z Score: -1,3, con impresión diagnóstica: osteoporosis secundaria, hiperparatiroidismo secundario e hipovitaminosis D3. Valoración por endocrinología prescribe calcitriol 0,50 mcg una tableta día y citrato de calcio 1.500 mg + vita- mina D3 200 UI dos tabletas diarias, remisión a odontología para definir manejo.

Conclusión: En pacientes sometidos a cirugía bariátrica tipo Y de Roux se sugiere evaluar previamente deficiencias de vitamina D3 además del seguimiento posoperatorio, garantizar suplencia nutricional adecuada con el fin de prevenir complicaciones propias de la osteoporosis, como fracturas que pueden conllevar a sedentarismo y recurrencia de la obesidad.

\title{
Póster
}

\section{Trastornos de la densidad mineral ósea en pacientes con enfermedad hepática crónica}

\author{
Guzmán GE, Zapata D, Manzi E, Jiménez D, Sepúlveda M, Serrano O, \\ Villegas J, Echeverri GJ, Caicedo LA.
}

Fundación Clínica Valle del Lilí, Cali, Colombia.

Introducción: La osteoporosis es un trastorno de la densidad mineral ósea frecuente en la enfermedad hepática crónica, especialmente en las etapas finales de la enfermedad, en algunas ocasiones asociada a fracturas que conlleva a bajos índices de calidad de vida y discapacidad. Así, describimos los trastornos de la densidad mineral ósea en pacientes con enfermedad hepática crónica evaluados para trasplante hepático en la Fundación Valle del Lilí.

Métodos: Estudio de corte transversal en pacientes con enfermedad hepática crónica evaluados para trasplante entre 2011 y 2013. Fueron elegibles pacientes mayores de 18 años. Se definió osteoporosis según criterios para densitometría de la OMS de acuerdo con la edad y sexo ( $T$ score $<-2,5$ DE o $Z$ score $<-2,0 \mathrm{DE}$ ). Se hizo análisis descriptivo con STATA $12^{\circledR}$.
Resultados: Un total de 150 pacientes fueron incluidos. Se encontró osteoporosis en 56 (37\%), osteopenia en 60 (40\%) y 34 (23\%) con resultado normal. En osteoporosis: 33 (59\%) fueron exclusivamente de compromiso de columna lumbar; femoral: 7 (12,5\%) y, concomitante: 16 (28,6\%). Según la etiología, los grupos con mayor prevalencia de osteoporosis fueron: virus de hepatitis $\mathrm{C}$ (VHC) y cirrosis biliar primaria (CBP) con prevalencia del 53\% (más frecuente en mujeres), seguida por alcohol del 40\%.

Conclusión: La osteoporosis y osteopenia son frecuentes en pacientes con cirrosis hepática. No solo en trastornos colestásicos sino también en VHC y alcohol principalmente en mujeres. Es necesario el seguimiento de la salud ósea una vez son trasplantados, dado el riesgo de fractura.

Palabras clave: cirrosis hepática, inmunosupresión, trasplante, osteoporosis, osteopenia. 